ENCYCLOPEDDIE Encyclopédie berbère

BERBERE

$36 \mid 2013$

36| Oryx - Ozoutae

\title{
Ours : Paléontologie
}

Djillali Hadjouis

\section{OpenEdition}

Journals

Édition électronique

URL : https://journals.openedition.org/encyclopedieberbere/3198

DOI : 10.4000/encyclopedieberbere.3198

ISSN : 2262-7197

\section{Éditeur}

Peeters Publishers

\section{Édition imprimée}

Date de publication : 2 juin 2013

Pagination : 5981-5982

ISBN : 978-2-7584-0194-0

ISSN : 1015-7344

\section{Référence électronique}

Djillali Hadjouis, «Ours : Paléontologie », Encyclopédie berbère [En ligne], 36 | 2013, document 052, mis en ligne le 12 mars 2021, consulté le 17 février 2022. URL : http://journals.openedition.org/ encyclopedieberbere/3198; DOI : https://doi.org/10.4000/encyclopedieberbere.3198

Ce document a été généré automatiquement le 17 février 2022.

(C) Tous droits réservés 


\title{
Ours : Paléontologie
}

\author{
Djillali Hadjouis
}

\section{NOTE DE L'ÉDITEUR}

[Ce texte est tiré de : Hadjouis, D., Atlas des mammifêres quaternaires et actuels d'Algérie, Editions Mille-feuilles, Alger, (sous-presse)].

1 L'ours brun est identifié avec certitude dans les gisements quaternaires d'Algérie et du Maghreb à partir du Paléolithique moyen, présent dans de nombreux abris-sous-roches et autres grottes fossilifères. L'espèce a été décrite pour la première fois en 1868 par Bourguignat sous l'appellation sub-spécifique de Ursus arctos larteti, puis de Ursus arctos faid'herbi. Aujourd'hui elle est connue sous le nom d'espèce de Ursus lartetianus.

Quand il décrit ces espèces d'ours (variété d'ours brun), Bourguignat est convaincu que l'ours vit encore en Algérie en 1870. Lors de l'exploration zoologique de l'Algérie au cours du XIX siècle, plusieurs auteurs ont reconnu et décrit la présence de cet Ursidé. Maurice Wagner dans son ouvrage sur l'Etude des mammiferes de l'Afrique mineure, indique la présence de cet animal. De même, le Dr Guyon en 1847 (In Seurat 1930) admet l'existence possible de l'ours, d'après le témoignage du peintre Horace Vernet. Ce dernier, lors de ses voyages en Algérie, aurait vu une peau d'ours à Annaba, provenant d'un animal tué dans les montagnes voisines.

3 Non satisfait des travaux de Bourguignat et de Pomel qui s'étaient contentés de décrire les fossiles d'Ursidés sous diverses appellations et sans indiquer les rapports qui existaient entre eux, Arambourg reprend dès 1932 l'étude paléontologique sur la base de nouveaux restes récemment livrés par les fouilles.

4 Les fossiles recueillis, de très bonne qualité de conservation, lui montrent qu'il s'agit d'un groupe dont les caractères mixtes relient les ours bruns (Ursus arctos) aux ours des cavernes (Ursus spelaeus) sur la base de caractères morphologiques dentaires, crâniens et du squelette des membres. Il montra que la spécialisation graduelle de ces Ursidés vers un régime de plus en plus omnivore tend à réduire progressivement les prémolaires dont certaines finissent par disparaître. Ce phénomène a favorisé le grand 
développement des arrières molaires au détriment des prémolaires. L'indice de grandeur de la quatrième prémolaire le montre par une décroissance depuis les formes les plus anciennes (Ursus arvernensis, U. etruscus, U. priscus, U. arctos, U. spelaeus).

5 Pour Arambourg comme pour Pomel avant lui, il considère que les espèces originaires d'Eurasie, devenant endémiques de l'Afrique du Nord, se caractérisent par quelques nuances de taille et de morphologie par rapport aux espèces souches eurasiatiques. Pour lui, l'ours brun par exemple est représenté par deux espèces: Une grande forme représentée par Ursus arctos larteti Bourguignat qui semble selon lui voisine d'Ursus priscus, présente dans les niveaux les plus anciens du Paléolithique et une petite forme Ursus arctos faid'herbi Bourguignat, succédant à la première en diminuant graduellement de taille. Cette même sous-espèce (appelée désormais Ursus lartetianus) paraît avoir persisté très tard dans le Djurdjura et les grands Massifs montagneux des Babors jusqu'à une époque très récente de l'histoire. Ces dernières années, des ossements d'ours brun ont été trouvés dans une grotte du massif de l'Akouker, datés par la méthode du carbone 14 entre 420 et 600 A.D. de l'époque historique (Hamdine et al. 1998).

\section{BIBLIOGRAPHIE}

ARAmbourg C., 1932 - «Révision des ours fossiles de l'Afrique du Nord », Ann. Mus. de Marseille, t. XXV, n² 2, p. 247-301.

BOURGUIGNAT J.-B., 1870 - Histoire du Djebel Thaya et des ossements fossiles recueillis dans la grande caverne de la mosquée. Paris, Challamel, 108 p.

HAMDINE W., THEVENOT M., MOCHAUX J., 1998 - « Histoire récente de l'ours brun au Maghreb », CRAS, III 321 (7), p. 565-570.

SEURAT L. G., 1930 - « Exploration zoologique de l'Algérie de 1830 à 1930 », Coll. du centenaire de lAlgérie, Etudes scientifiques, Paris, Masson et $\mathrm{C}^{\text {ie }} \mathrm{Ed}$.

INDEX

Mots-clés : Paléontologie, Zoologie 